\title{
Eclampsia: a comparative study in a tertiary hospital setting in South- South Region of Nigeria
}

\author{
Eugene M. Ikeanyi*, Isaac J. Abasi
}

Department of Obstetrics and Gynecology, Niger Delta University Teaching Hospital Okolobiri, Bayelsa State, Nigeria

Received: 08 April 2020

Accepted: 30 April 2020

\section{*Correspondence:}

Dr. Eugene M. Ikeanyi,

E-mail: abuchikeanyi@yahoo.com

Copyright: (C) the author(s), publisher and licensee Medip Academy. This is an open-access article distributed under the terms of the Creative Commons Attribution Non-Commercial License, which permits unrestricted non-commercial use, distribution, and reproduction in any medium, provided the original work is properly cited.

\begin{abstract}
Background: Eclampsia remains a leading cause of maternal and perinatal morbidity and mortality often in settings of poor health seeking behaviour and services. Objective of this study was to determine the incidence, investigate the risk factors, obstetric outcomes and suggest ways of improving the impact of eclampsia.

Methods: An analytical observational study on consecutive cases of eclampsia managed in a tertiary hospital setting from 2014 to 2019. For each case of eclampsia recruited the next gestational hypertensive and normotensive cases managed in the period were recruited to serve as controls. Computer statistical software, Chi square for test of associations were used for analysis with statistical significance set at $\mathrm{p}<0.05$.

Results: Among 3625 deliveries within the study period were 57 cases of eclampsia; an incidence of $1.57 \%$. Most $(74.4 \%)$ were antepartum eclampsia. Majority of the eclamptic mothers were unbooked $(81.4 \%)$, of lower social class $(86.0 \%)$, poorly educated $(81.4 \%)$ and nulliparous $(58.1 \%)$. Eclamptic mothers were more likely to be youth $\leq 24$ years $(39.5 \%)$, teenagers $(25.6 \%)$, and unmarried. Twenty-four $(55.8 \%)$ had abdominal delivery, anaemia (23.3\%) and were transfused. Three women died from eclampsia; a case fatality of $6.98 \%$. Twenty-four $(55.8 \%)$ neonates were preterm, low birth weight $(48.8 \%)$, intrauterine growth restriction $(25.6 \%)$, special care baby unit admission $(32.6 \%)$ and perinatal mortality $13(30.2 \%)$.

Conclusions: Eclampsia is still an un-mitigating malady in this study settings with increased maternal and perinatal complications. Nulliparity, low social status, young age and lack of prenatal care appeared significant risk factors. Quality prenatal care, early detection and management of pre-eclampsia will mitigate eclampsia occurrence and severity. Women empowerment is proffered.
\end{abstract}

Keywords: Eclampsia, Incidence, Maternal, Nigeria, Outcome, Perinatal, Risk factors

\section{INTRODUCTION}

Eclampsia remains a leading maternal morbidity and a major cause of maternal and perinatal death mostly in settings of poor healthcare services and or health seeking behaviour. It is basically grand mal seizure disorder in pregnancy occurring in a background of gestational hypertension and absence of other known causes of seizure. The aetiology of pre-eclampsia-eclampsia is poorly understood and largely shroud in theories.
Eclampsia is part of the end of the spectrum of preeclampsia thought to be associated with hypertensive encephalopathy, cerebral vasospasm, ischemia, vasogenic oedema and endothelial damage. ${ }^{1,2}$ Eclampsia is evidently preventable pregnancy-related disorder globally known to be more prevalent in low resource settings and rare in industrialized countries. The incidence of gestational hypertension unlike its complication eclampsia is about uniform globally. Eclampsia is rare and almost stable at 4-5 cases per 10,000 live births in industrialized countries 
like the United States of America and the United Kingdom but common at 6-100 cases per 10,000 live births in developing countries. ${ }^{2}$ Its morbidity is multisystem resulting in acute renal damage, cardiopulmonary, hepatic, haematological and placental dysfunction. The resultant placenta dysfunction accounts for poor foetal outcome. Eclampsia accounts for 50,000 maternal deaths annually globally. ${ }^{3}$ There has been a number of identifiable risk factors for eclampsia. ${ }^{4,5}$ Its incidence varies from one society to another just as the outcomes. ${ }^{4,5}$ The observed regional differences are not biological but related to behavioural and healthcare delivery system. Relative high occurrence and worse outcome in developing countries can be attributed to the lack of prenatal care largely due to limited accessibility and affordability of health care, late referral and high patronage of non-orthodox health care in developing countries. Regional documentations of the risk factors, incidence and outcomes of eclampsia will not only help in providing national data but add to the global body of knowledge and strategies to curb its impact.

\section{METHODS}

An analytical observational study of cases of eclamptic mothers as the study group with those of gestational hypertension and normotensive mothers respectively as the control groups to enable exploration of risk factors and the effects of eclampsia by comparisons was conducted between 2014 and 2019 at Niger Delta University Teaching Hospital (NDUTH), Bayelsa State in Nigeria. The study centre is a tertiary health institution with the major roles of teaching, research and health services. The study was in the obstetrics and gynecology department of the hospital. The centre is domicile at Bayelsa state as the leading referral centre to other health facilities within and outside the state. Bayelsa State is one of the oil-rich states of the Niger delta region of Nigeria. The Izons are the dominant ethnic group with residents from other parts of Nigeria and the globe. The traditional occupations are farming, fishing and trading. Data were collected on each case of eclampsia managed within the study timeline. For each case of eclampsia recruited, the next eligible cases of gestational hypertension and normotensive mothers were similarly respectively recruited for comparison. Each participant's case file, labour ward and obstetric theatre records were reviewed for data on sociodemographic (age in years, parity, marital status, educational status, spouse occupation), maternal and perinatal complications. The social class was determined according to Olusanya et al but sub grouped into upper class (classes I and II) and lower class (classes III, IV and V). ${ }^{6}$ Pregnancies complicated by eclampsia, gestational hypertension and normotensive ones managed at the study centre within the study period were eligible to be included in the study. Cases of chronic hypertension, unexplained proteinuria in pregnancy and multifetal pregnancies were excluded from the study. Every known unrelated neurological disorder like epilepsy in pregnancy was also excluded from the study.
Gestational hypertension was blood pressure $\geq 140 / 90$ $\mathrm{mmHg}$ with or without significant proteinuria (catheter specimen of urine with at least one + of proteinuria with dipstick or $300 \mathrm{mg} / 24$-hour urine) first noted in the second half of pregnancy $(\geq 20$ weeks $)$ in a mother previously normotensive and non-proteinuric. Eclampsia is seizure activity or coma unrelated to other cerebral conditions in an obstetric patient with gestational hypertension. Normotensive cases had neither gestational hypertension nor eclampsia. All the deliveries that took place in the study period were noted. The process of data collection did not involve subject identifiers therefore did not require individual subject consent.

\section{Statistical analysis}

The data was collated in EPI Info computer software used for analysis. Fisher's exact statistical package was used for test of associations of proportions of categorical variables as odd ratio while univariate analysis as frequency, mean and standard deviation for continuous variables. Student's t-test was used for comparison of the mean. Statistical significance was set at $\mathrm{p}<0.05$. The relative risks of eclampsia were estimated as odds ratios (OR).

\section{RESULTS}

There were 57 cases of eclampsia among 3625 deliveries, an incidence of $1.57 \%$. Only 43 case files could be retrieved or had complete data for analysis $75.4 \%$ retrieval rate and these were used for subsequent analysis. Thirty-two $(74.4 \%)$ of these had eclamptic fits before onset of labour, six (14.0\%) intrapartum while five (11.6\%) had it postpartum.

Table 1 shows the characteristics of the participants. The participants who suffered eclampsia were significantly younger than the control counterparts $p<0.001$. Relative to gestational hypertension group, there were fourteenfold likelihood of teenagers in study group and this increased to over thirty-two folds when compared with normotensive group. These findings were statistically significant $\mathrm{p}<0.01$. The study group was more than eighteen-fold at increased likelihood of being unmarried relative to gestational hypertensive group and about sixfold to the normotensive group. The observed differences were statistically significant $\mathrm{p}<0.01$.

Though, the participants were on average comparable in parity $(\mathrm{p}>0.05)$, the study group compared with the gestational hypertensive group was about thrice (OR 2.9, $\mathrm{p}=0.03$ ) and fivefold (OR 5.6, $\mathrm{p}=0.0004$ ) with normotensive group, more likely to be nulliparous. Though the study group was comparable educationally with control groups, it was more than doubled and insignificantly more likely to be of lower educational level than the normotensive group $(p>0.05)$. The study group was more than fourfold more likely to be unbooked for prenatal care relative to control groups. The observed 
difference was statistically significant $\mathrm{p}<0.01$. The study group had insignificantly shorter interpregnancy interval relative to gestational hypertensive control group but longer than normotensive group $\mathrm{p}>0.05$ respectively.

Table 1: Characteristics of participants and risk of eclampsia N=131.

\begin{tabular}{|c|c|c|c|c|c|c|}
\hline Characteristic & Variable & $\begin{array}{l}\text { Eclampsia } \\
\mathrm{n}=\mathbf{4 3}(\%)\end{array}$ & $\begin{array}{l}\text { GHPN } \\
n=43(\%)\end{array}$ & $\begin{array}{l}\text { Normotensive } \\
\mathrm{n}=45(\%)\end{array}$ & $\begin{array}{l}\text { EC versus GHTN } \\
\text { OR: } p \text {-value }\end{array}$ & $\begin{array}{l}\text { EC versus NTN } \\
\text { OR: p-value }\end{array}$ \\
\hline \multirow{6}{*}{ Age (years) } & $\leq 19$ & $11(25.6 \%)$ & $1(2.3 \%)$ & $0(0 \%)$ & \multirow{6}{*}{ 14.4: 0.003} & \multirow{6}{*}{ 32.2: 0.002} \\
\hline & $20-24$ & $6(13.9 \%)$ & $4(9.3 \%)$ & $7(15.6 \%)$ & & \\
\hline & $25-29$ & $8(18.6 \%)$ & $7(16.3 \%)$ & $7(15.6 \%)$ & & \\
\hline & $30-34$ & $9(20.9 \%)$ & $13(30.2 \%)$ & $17(37.8 \%)$ & & \\
\hline & $\geq 35$ & $9(20.9 \%)$ & $18(41.9 \%)$ & $14(31.1 \%)$ & & \\
\hline & Mean \pm SD & $27.1 \pm 8$ & $32.1 \pm 6.5$ & $32.0 \pm 5.6$ & & \\
\hline \multirow{2}{*}{ Marital status } & Unmarried & $13(30.2 \%)$ & $1(2.3 \%)$ & $3(6.7 \%)$ & \multirow{2}{*}{ 18.2: 0.007} & \multirow{2}{*}{ 6.1: 0.005} \\
\hline & Married & $30(69.8 \%)$ & $42(97.7 \%)$ & $42(93.3 \%)$ & & \\
\hline \multirow{3}{*}{ Parity } & 0 & $25(58.1 \%)$ & $14(32.6 \%)$ & $9(20.0 \%)$ & \multirow{3}{*}{ 2.9: 0.03} & \multirow{3}{*}{ 5.6: 0.0004} \\
\hline & $\geq 1$ & $18(41.9 \%)$ & $29(67.4 \%)$ & $36(80.0 \%)$ & & \\
\hline & Mean \pm SD & $1.5 \pm 2.5$ & $1.8 \pm 1.9$ & $2.2 \pm 2.0$ & & \\
\hline \multirow{2}{*}{ Social class } & Upper & $6(14.0 \%)$ & $12(27.9 \%)$ & $13(28.9 \%)$ & \multirow{2}{*}{$0.42: 0.18$} & \multirow{2}{*}{ 0.40: 0.12} \\
\hline & Lower & $37(86.0 \%)$ & $31(72.1 \%)$ & $32(71.1 \%)$ & & \\
\hline \multirow{2}{*}{ Education } & $\leq 2^{0}$ & $35(81.4 \%)$ & $26(60.5 \%)$ & $29(64.4 \%)$ & \multirow{2}{*}{ 2.9: 0.06} & \multirow{2}{*}{ 2.4: 0.10} \\
\hline & $>2^{0}$ & $8(8.6 \%)$ & $17(39.5 \%)$ & $16(35.6 \%)$ & & \\
\hline \multirow{2}{*}{ Booking status } & Unbooked & $35(81.4 \%)$ & $21(48.8 \%)$ & $5(11.1 \%)$ & \multirow{2}{*}{ 4.6: 0.003} & \multirow{2}{*}{ 35.0: 0.0001} \\
\hline & Booked & $8(18.6 \%)$ & $22(51.2 \%)$ & $40(88.9 \%)$ & & \\
\hline $\begin{array}{l}\text { Interpregnancy } \\
\text { interval }\end{array}$ & Mean \pm SD & $46.1 \pm 29.5$ & $67.9 \pm 45.9$ & $39.6 \pm 20.2$ & $\mathrm{p}=0.10$ & $\mathrm{p}=0.34$ \\
\hline
\end{tabular}

GHTN: Gestational hypertension, EC: Eclampsia, NTN: Normotensive.

Table 2: Maternal outcomes in the participants $\mathrm{N}=131$.

\begin{tabular}{|llllll|}
\hline Variables & $\begin{array}{l}\text { Eclampsia } \\
\mathbf{n}(\%)\end{array}$ & $\begin{array}{l}\text { GHPN } \\
\mathbf{n}(\%)\end{array}$ & $\begin{array}{l}\text { Normotensive } \\
\mathbf{n}(\%)\end{array}$ & $\begin{array}{l}\text { EC versus GHTN } \\
\text { OR: } \mathbf{p} \text {-value }\end{array}$ & $\begin{array}{l}\text { EC versus NTN } \\
\text { OR: } \mathbf{p} \text {-value }\end{array}$ \\
\hline Mean SBP $(\mathrm{Hg})$ & $182.6 \pm 32.0$ & $173.7 \pm 27.3$ & $115.1 \pm 12.4$ & $\mathrm{p}=0.17$ & $\mathrm{p}<0.0001$ \\
\hline Mean DBP $(\mathrm{Hg})$ & $114.2 \pm 24.6$ & $107.3 \pm 17.3$ & $72.2 \pm 11.1$ & $\mathrm{p}=0.14$ & $\mathrm{p}<0.0001$ \\
\hline Caesarean section & $24(55.8 \%)$ & $35(81.4 \%)$ & $6(13.3 \%)$ & $0.29: 0.02$ & $8.2: 0.0001$ \\
\hline Anaemia & $10(23.3 \%)$ & $5(11.6 \%)$ & $1(2.2 \%)$ & $2.3: 0.26$ & $13.3: 0.003$ \\
\hline Acute renal failure & $1(2.3 \%)$ & $0(0.0 \%)$ & $0(0.0 \%)$ & - & - \\
\hline Thrombocytopenia & $1(2.3 \%)$ & $0(0.0 \%)$ & $0(0.0 \%)$ & - & - \\
\hline Cerebrovascular accident & $1(2.3 \%)$ & $0(0.0 \%)$ & $0(0.0 \%)$ & - & - \\
\hline Long hospital stays & $19(44.2 \%)$ & $13(30.2 \%)$ & $3(6.7 \%)$ & $1.8: 0.26$ & $11.1: 0.0001$ \\
\hline Postpartum haemorrhage & $2(4.7 \%)$ & $7(16.3 \%)$ & $1(2.2 \%)$ & $0.25: 0.16$ & - \\
\hline Pulmonary oedema & $1(2.3 \%)$ & $1(2.3 \%)$ & $0(0.0 \%)$ & - & 6.51 \\
\hline Transfusion & $10(23.3 \%)$ & $16(37.2 \%)$ & $2(4.4 \%)$ & $0.51: 0.24$ & - \\
\hline LGT laceration & $0(0.0 \%)$ & $0(0.0 \%)$ & $1(2.2 \%)$ & - & - \\
\hline Puerperal sepsis & $1(2.3 \%)$ & $1(2.3 \%)$ & $0(0.0 \%)$ & - & - \\
\hline Mortality & $3(6.98 \%)$ & $0(0.0 \%)$ & $0(0.0 \%)$ & - & \\
\hline
\end{tabular}

GHTN: Gestational hypertension, EC: Eclampsia, NTN: Normotensive.

Table 2 shows maternal complications of the participants. The study group has similar mean blood pressure to gestational hypertensive group ( $p>0.05$ ) but significantly higher than that of normotensive group; systolic blood pressure (SBP) 182.6 versus $115.1 \mathrm{mmHg}$ and diastolic blood pressure (DBP) 114.2 versus $72.2 \mathrm{mmHg}, \mathrm{p}<0.001$.
Twenty-five $(58.1 \%)$ of the eclamptic mothers had severe hypertension with diastolic blood pressure (DBP) $\geq 110$ $\mathrm{mmHg}$ while $35(81.4 \%)$ had systolic $\mathrm{BP} \geq 160 \mathrm{mmHg}$. The composite complications for the participants was 72 (167.4\%) versus $78(181.4 \%)$ versus $14(13.1 \%)$ for eclampsia, gestational hypertensive and normotensive 
groups respectively. Twenty-nine of the eclampsia group had $\geq 2+$ proteinuria. The study group was approximately $70 \%$ less likely but more than eight-fold more likely to deliver per abdomen when compared with the gestational hypertensive and normotensive subsets respectively. The observed differences were significant $\mathrm{p}<0.01$. Sixteen $(12.2 \%)$ of the participants suffered anaemia consisting of $10(23.3 \%)$ of study group, five $(11.6 \%)$ of gestational hypertensive and one $(2.2 \%)$ of normotensive groups respectively. The observed differences were similar but noteworthy when the study group was related to the control groups $\mathrm{p}=0.26$ and $\mathrm{p}=0.003$ respectively. The data also showed that relative to the gestational hypertensive group, the study group was about $73 \%$ less likely to suffer postpartum haemorrhage but more than doubled the risk when compared with the normotensive group. Nonetheless the observed differences were not significant $p>0.05$. This further reflected in the risk of blood transfusion among the subgroups with reduced risk relative to gestational hypertensive but increase to about sevenfold and significant with normotensive subgroup $\mathrm{p}=0.013$. Though the eclamptic group has about double the likelihood of long hospital stay relative to gestational hypertensive group, nonetheless this was not statistically significant (OR:1.8, $\mathrm{p}=0.26$ ). On the contrary this likelihood increased to about eleven-fold and was significant when the former was compared with the normotensive group (OR: 11.1, $\mathrm{p}<0.001$ ). The study group suffered acute renal failure ARF (2.3\%), pulmonary oedema $(2.3 \%)$, cerebrovascular accident $(2.3 \%)$, thrombocytopenia $(2.3 \%)$ and $3(6.98 \%)$ died from eclampsia. On the contrary, with the exception of one case of gestational hypertension group complicated by pulmonary oedema, none of the control groups had any of these complications or suffered mortality.

Table 3: Perinatal complications of participants $\mathrm{N}=131$.

\begin{tabular}{|c|c|c|c|c|c|}
\hline Variable & $\begin{array}{l}\text { Eclampsia } \\
n=43(\%)\end{array}$ & $\begin{array}{l}\text { GHPN } n=43 \\
(\%)\end{array}$ & $\begin{array}{l}\text { Normotensive } \\
\mathrm{n}=\mathbf{4 5}(\%)\end{array}$ & $\begin{array}{l}\text { EC versus GHTN } \\
\text { OR: } p \text {-value }\end{array}$ & $\begin{array}{l}\text { EC versus NTN } \\
\text { OR: p-value }\end{array}$ \\
\hline Mean delivery GA (weeks) & $34.6 \pm 4.5$ & $35.6 \pm 4.3$ & $39.0 \pm 2.7$ & $>0.05$ & $<0.001$ \\
\hline Mean birth weight (gms) & $2294.4 \pm 975$ & $2416.5 \pm 984.3$ & $3161.1 \pm 489.0$ & $>0.05$ & $<0.001$ \\
\hline ENND & $4(9.3 \%)$ & $2(4.7 \%)$ & $0(0.0 \%)$ & 2.1: 0.68 & 10.4: 0.05 \\
\hline FSB & $7(16.3 \%)$ & $5(11.6 \%)$ & $0(0.0 \%)$ & $1.5: 0.76$ & 18.7: 0.005 \\
\hline MSB & $2(4.7 \%)$ & $1(2.3 \%)$ & $0(0.0 \%)$ & $2.0: 1.0$ & \\
\hline Preterm birth & $24(55.8 \%)$ & $24(55.8 \%)$ & $7(15.6 \%)$ & $1.0: 1.17$ & 6.9: 0.001 \\
\hline $\mathrm{A} / \mathrm{S}<7$ at $5 \mathrm{~min}$ & $18(41.9 \%)$ & $13(30.2 \%)$ & $1(2.2 \%)$ & 1.7: 0.37 & 31.7: 0.0001 \\
\hline Low birth weight & $21(48.8 \%)$ & $24(55.8 \%)$ & $3(6.7 \%)$ & 0.76: 0.67 & 13.4: 0.0001 \\
\hline SGA & $11(25.6 \%)$ & $12(27.9 \%)$ & $0(0.0 \%)$ & 0.89: 1.0 & - \\
\hline Stillbirth & $9(20.9 \%)$ & $6(14.0 \%)$ & $0(0.0 \%)$ & 1.6: 0.57 & - \\
\hline SCBU admission & $14(32.6 \%)$ & $14(32.6 \%)$ & $1(2.2 \%)$ & $1.0: 1.2$ & - \\
\hline Perinatal death & $13(30.2 \%)$ & $8(18.6 \%)$ & $0(0.0 \%)$ & 1.9: 0.32 & - \\
\hline
\end{tabular}

GHTN: Gestational hypertension, EC: Eclampsia, NTN: Normotensive.

Table 3 shows the perinatal complications of the participants. There was statistically significant difference in the gestational age at delivery of the neonates of the three subsets of the participants $(p<0.001)$. However, the neonates were born to the eclampsia and gestational hypertensive groups at similar gestational age $(\mathrm{p}>0.05)$. This reflected in their different relative birth weights $(\mathrm{p}>0.05)$ and $(\mathrm{p}<0.001)$ respectively. There were 13 $(30.2 \%)$ perinatal death in eclampsia group; an approximately twice that in the gestational hypertensive group and none occurred in the normotensive group. Preterm birth was high among the eclampsia group at $55.8 \%$ similar to gestational hypertensive group $(\mathrm{p}>0.05)$ but significantly higher than in normotensive (OR 6.9, $\mathrm{p}<0.001)$. The rate of poor Apgar score at 5 minute at $41.9 \%$ among neonates born to the mothers in the eclampsia group was higher than the rate in the gestational hypertensive group though there was no statistical difference $(\mathrm{p}=0.37)$. On the contrary the rate in the study group became significantly higher when compared with the rate in the normotensive subset $\mathrm{p}<0.001$. Low birth weight rate was $48.8 \%$ among neonates of eclampsia group and statistically similar to those of gestational hypertensive group but significantly higher than normotensive group $<0.001$. Small for gestational age neonates were recorded in $25.6 \%$ of the eclampsia group and this was statistically similar to that in the gestational hypertensive group. Special care baby unit admission (SCBU) was $32.6 \%$ in both the eclampsia and gestational hypertensive groups respectively.

Twenty-four $(55.8 \%)$ versus $24(55.8 \%)$ versus 7 (15.6\%) of the new-borns of the eclampsia, the gestational hypertensive and the normotensive mothers respectively were delivered preterm (Figure 1). The eclampsia group had the highest incidence of extreme preterm delivery (11.5\%) The new-borns delivered at $\geq 37$ weeks were 19 $(44.2 \%)$ in eclampsia group, same in gestational hypertensive group and $38(84.4 \%)$ in normotensive group. 


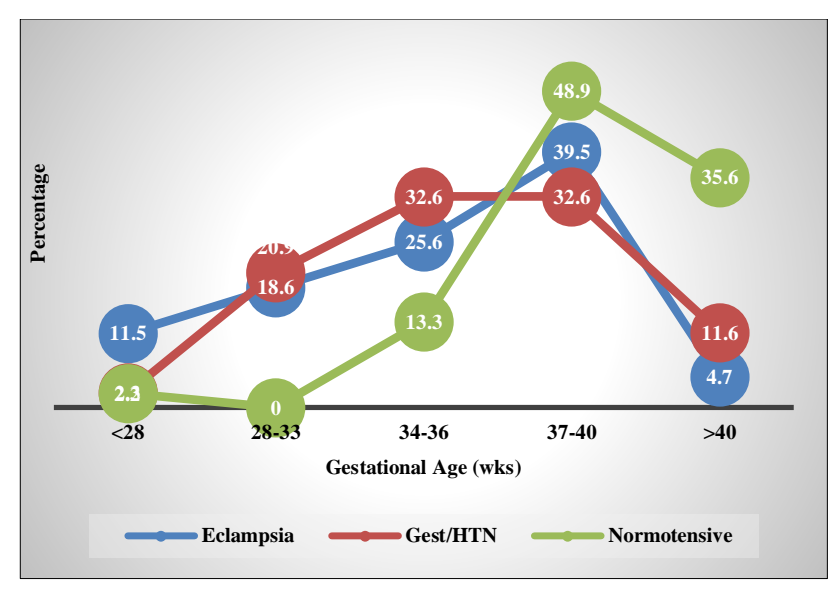

Figure 1: Gestational age at delivery of neonates by subsets of participants.

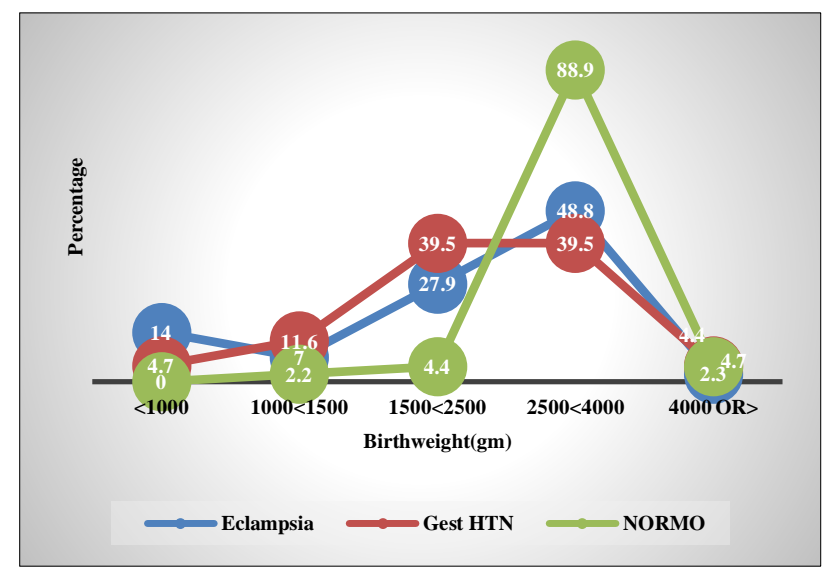

Figure 2: Birth weight of neonates by subsets of participants.

Figure 2 shows the birth weight of participants' newborns. Twenty-one $(48.8 \%)$ of the new-borns of the eclampsia group were low birth weight compared with 24 $(55.8 \%)$ and $3(6.7 \%)$ for gestational hypertensive and normotensive control groups respectively. Twenty-two $(51.2 \%), 19(44.2 \%)$ and $42(93.3 \%)$ of the new-borns of the eclampsia group, gestational hypertensive and normotensive weighed $\geq 2500$ grams at birth respectively.

\section{DISCUSSION}

The incidence of eclampsia in this data was $1.57 \%$.This was lower than $1.99 \%$ in Benin city, $1.7-2.1 \%$ in South West $4.4 \%$ in a 10-year data in northern Nigeria and $2.45 \%$ from Southeast Nigeria, higher than $0.64-1.48 \%$ in India, $1.12-1.25 \%$ from another report from southeast Nigeria and comparable to $1.32 \%$ reported in Gwagwalada an area council in Abuja, the Federal capital territory (FCT) of Nigeria and another report from Benin city $1.32 \% .^{1,4,5,7-14}$ This was however higher than $0.76 \%$ by another team of researchers from Abuja Metropolitan area of FCT Nigeria. ${ }^{15}$ The latter was based only on the data from intensive care admissions unlike the study data that included all the eclampsia cases managed in the study period at the centre. The case fatality of $6.98 \%$ was higher than a maximum of $1 \%$ recommended by United Nations. ${ }^{16}$ The incidence was higher than 0.47 per 10,000 maternities in UK and $0.5-2 \%$ of the $5 \%$ cases of preeclampsia that progress to eclampsia in the United State..$^{3.17}$ The majority $(74.4 \%)$ of the eclampsia cases in this study were antepartum. This was similar to reports from Sokoto in northwest of Nigeria, Abuja the FCT of Nigeria, Nnewi in the Southeast and Benin city in Southsouth. ${ }^{4,7,18-21}$ This was however lower than reports from India where about nine out of every ten cases were antepartum eclampsia. ${ }^{1,11,12}$ This was in contrast to a report from northern Nigeria where the majority of the eclamptic fits were intrapartum. ${ }^{9}$ Most of these women in this study data did not benefit from prenatal care for early detection and management at pre-eclamptic stage before progression to eclampsia. They were largely referred cases following eclamptic fits. Mothers in this setting tend to preferably access traditional birth attendance (TBA) homes, health centres and private health facilities for reasons of proximity and affordability and are largely referred for quality care late. For instance, each of the five cases of postpartum eclampsia in this data delivered at home or TBA homes and were brought in only at antecedent fits. Similarly, the intrapartum cases presented following fits in labour outside the study centre. The preeclamptic women who present at the study centre before fit are proactively managed among other measures with the adequate dose of magnesium sulphate to prevent fits. It is evident from the Magpie trial; a randomized placebo controlled trial that magnesium sulphate given in labour and for at least 24 hours postpartum will reduce by more than half $(58 \%)$ the risk of eclampsia in severe preeclampsia or imminent eclampsia. ${ }^{22}$ The mean age of the mothers managed for eclampsia in study data was 27.1 years and was comparable to that of other researchers. ${ }^{5,7,14,15}$ This was higher than the mean age reported in another study. ${ }^{9,11,12}$ The cases in study data were mostly young mothers $(39.5 \%)$ especially the teenagers who constituted $25.6 \%$ of all the cases corroborating other reports. ${ }^{7,8,11,23,24}$ This was in contrast to higher age incidence reported by other researchers. ${ }^{4,19-}$ 20 The teen mothers and those $\geq 35$ years belong to the groups at the extremes of reproductive age profusely associated in the literature with increased risk of preeclampsia-eclampsia. ${ }^{3}$ especially if it were first delivery. Mothers who were unbooked and did not have prenatal care were more prone to eclampsia in-keeping with other reports. ${ }^{7,12,22,23}$ Early detection and quality care of cases of pre-eclampsia not only reduces the incidence but the adverse outcomes of eclampsia. This explains the relative low incidence of eclampsia in industrialized societies with high level of maternal awareness and quality healthcare system. Eclampsia has been largely associated with inadequate prenatal care and high prevalence of poverty. This was corroborated in this data by the high incidence of the disorder among the mothers with low socioeconomic state similar to other reports in the literature. ${ }^{24,25}$ Eclampsia was recorded mostly (58.1\%) among the nulliparous mothers and this was comparable 
to the reports from southeast Nigeria, southwest Nigeria, Benin city and FCT Abuja Nigeria corroborating other reports in the literature. , $^{3,7,8,10,17,20,21}$ This was however, lower than the reports from northern Nigeria and India. ${ }^{9,11}$ Study data showed that mothers who were unmarried, poorly educated, of low socioeconomic status therefore mostly unsupported and subsequently lacked quality prenatal care were the candidates for eclamptic fits, thus supporting other reports. ${ }^{5,9,23,24}$ Most (58.1\%) of the eclamptic mothers in this data had severe hypertension with diastolic blood pressure of $\geq 110 \mathrm{mmHg}$ on diagnosis and admission. This was comparable to other reports where $48.5-69.6 \%$ cases of eclampsia had severe hypertension. ${ }^{1,4}$

In this data, three eclamptic mothers each respectively had acute pulmonary oedema, acute renal failure and cerebrovascular accident. Three of the eclamptic mothers died, a case fatality of $6.98 \%$. This was higher than $3.57 \%$ in India 12 and lower than $8.3-20.0 \%$ in South West Nigeria 8.5-28.2\% in FCT Abuja Nigeria and 17.9$22.3 \%$ in the northern Nigeria, $10.7-15.96 \%$ in Benin City and $9.3-17.7 \%$ in the southeast region. ${ }^{4,5}$, $9,14,15,20,21,26$ The observed difference in case fatality can be ascribed to the promptness in presentation and diagnosis coupled with the level of aggressiveness and quality of management of the cases. The longer the time interval of the onset of fits and or the higher the number of the fit episodes before commencement of quality intervention the worse the maternal outcome and higher the mortality in eclampsia. Most of the women in this study data were referred in advanced state of the disorder. In the United States, eclampsia related maternal death has been brought below $1 \%$ for reasons of the promptness at presentation of cases and the quality of the care given. ${ }^{3}$

Quality prenatal care offers not only health talks on the right nutrition among other issues, but provides malaria chemoprophylaxis, hematinic, vitamins and other minerals to the deficiency of which some workers directly or indirectly ascribed the trigger role for eclampsia. ${ }^{24,27,28}$

A minimum of four prenatal care visits has been recommended by World Health Organization (WHO) for maternal and foetal wellbeing. ${ }^{11,29}$ One particular study ascribed increased risk of preeclampsia to diet pattern high in processed meat, salty snacks and sweet drinks while diets on vegetables, fruits, vegetable oil, plant foods, are noted to be protective against preeclampsia. ${ }^{30}$ Quality prenatal care inter alia, entails a combination of a compliant client and dedicated health provider to ensure regular evaluation to promptly detect rising blood pressure, proteinuria and prompt care before progression to seizure.

The majority of eclampsia group had caesarean delivery $(55.8 \%)$. This corroborated similar findings of 54.2$74.6 \%$ in other reports. ${ }^{5,11,20}$ This was, however, in contrast to reports of fewer caesarean deliveries than vaginal deliveries. ${ }^{12,13}$ The high rate of caesarean delivery was in an effort to save the salvageable preterm neonates and those with foetal distress frequent in cases of eclampsia. Most of the eclamptic mothers with viable foetus and unfavorable cervix are stabilized clinically and delivered by the safest and fastest route, in this case, largely caesarean section as many of the eclampsia cases are remote from term and are not in labour. Mothers who suffered eclampsia stayed longer in hospital admission due to high rates of preterm birth and severe maternal complications. Eclampsia is a significant contributor to iatrogenic preterm delivery $(55.8 \%)$ in this data. This was comparable to the report by other researchers. ${ }^{20}$ It was evident that the neonates of eclamptic mothers that were delivered by caesarean section had better neonatal survival when compared with those who had vaginal delivery. ${ }^{5,7}$ There was increased prevalence of anaemia among the eclampsia group corroborating another report. $^{24}$

This can be attributed to the increased incidence of caesarean delivery in the subset. About two out of every five neonates delivered to mothers who had eclampsia in this study data, required admission into special care baby unit (SCBU).

The various indications for special care baby unit admission from this study data included the over half of the neonates delivered preterm and premature $(55.8 \%)$, about half that had birth asphyxia (41.9\%), low birth weight $(48.8 \%)$ and a quarter $(25.6 \%)$ that suffered intrauterine growth restriction (IUGR). Eclampsia has been associated with high rates of preterm birth. ${ }^{1,14,20}$ This coincided with the high rate of prematurity recorded among the neonates of mothers who had eclampsia in this study. The high rate of perinatal death in eclampsia was attributable to the high incidence of prematurity inherent in neonates delivered to eclamptic mothers.

This is because the timely termination of pregnancy complicated by severe pre-eclampsia - eclampsia marks the beginning of the recovery from the eclampsia malady. Perinatal mortality of $30.2 \%$ in this study was comparable to $31.03 \%$ by another report 1 , higher than $21.4-24.1 \%$, but lower than a report from another region in Nigeria. ${ }^{5,9,14}$

Values as high as $12 \%$ perinatal death is still obtainable in developed countries 3 making eclampsia one of the leading global causes of perinatal morbidity and wastage. This study drew its strength in its study design and the randomized sampling technique. The conclusions thereof would have been more generalizable if the study were multicenter and data prospectively generated.

\section{CONCLUSION}

Eclampsia is a pregnancy-specific disorder with increased incidence and adverse obstetric outcome largely among young, unbooked, unmarried, poorly educated, low class 
and nulliparous mothers. Women empowerment, family planning services for pregnancy timing, quality prenatal care to ensure early detection and management of preeclampsia before it progresses to eclampsia and its adverse outcome will substantially mitigate the negative impact of eclampsia to the level as obtains in the developed countries.

Funding: No funding sources

Conflict of interest: None declared

Ethical approval: Not required

\section{REFERENCES}

1. Lavanya SG, Ganitha G. A prospective study of pregnancy outcome in eclampsia. Indian $\mathrm{J}$ Obstet Gynecol Res. 2017;4(1):26-2.

2. Sharara HA. A review of eclampsia in Qatar: a twenty-year study (from January 1991- December 2009). Qatar Med J. 2012;2:7-15.

3. Fugate SR, Chow GE. Eclampsia. In: Emedicine.com Oct ,2005.

4. Agida ET, Adeka BI, Jibril KA. Pregnancy outcome in eclamptic at the University of Abuja Teaching Hospital, Gwagwalada, Abuja: A 3 year review. Niger J Clin Pract. 2010;13:394-8.

5. Adekanle DA, Akinbile TO. Eclampsia and pregnancy outcome at Lautech Teaching Hospital, Osogbo, South West, Nigeria. Clinics Mother Child Health. 2012;9(1):1-4.

6. Olusanya O, Okpere EE, Ezimokhai M. The importance of social class in voluntary fertility control in a developing country. West Afr J Med. 1985;4:205-12.

7. Okoror CEM. Maternal and perinatal outcome in women with eclampsia: a retrospective study at the University of Benin Teaching Hospital. Int J Reprod Contracept Obstet Gynecol. 2019;8(1):108-14.

8. Olatunji AO, Sule Odu AO. Presentation and outcome of eclampsia at a Nigerian University Hospital. Niger J Clin Pract. 2007;10(1):1-4.

9. Adamu AN, Ekele BA, Ahmed Y, Mohammed BA, Isezuo SA, Abdullahi AA. Pregnancy outcome in women with eclampsia at a tertiary centre in northern Nigeria. Afr J Med Med Sci. 2012;41(2):211-9.

10. Umezulike CC, Feyi Waboso PA, Whittaker RC Treatment of eclampsia with magnesium sulphate in Aba, South- Eastern Nigeria. Trop J Obstet Gynaecol. 2006;23(1):20-2.

11. Ghosh MD, Singh V, Ray A. Maternal and foetal outcome of eclampsia in a referral hospital. Int J Reprod Contracept Obstet Gynecol. 2017;6(3):10214.

12. Dora SK, Nayak L, Pande B, Dandapat AB. A prospective observational study for the evaluation of maternal and fetal outcome in patient with eclampsia. Int J Res Med Sci. 2017;5:1785-9.

13. Esike CO, Chukwuemeka UI, Anozie OB, Eze JN, Aluka OC, Twomey DE. Eclampsia in Rural Nigeria:
The unmitigating Catastrophe. Ann Afr Med 2017; $16: 175-80$.

14. Onuh SO, Aisien AO. Maternal and fetal outcome in eclamptic patients in Benin City, Nigeria. J Obstet Gynaecol. 2004;24(7):765-8.

15. Okafor UV, Efetie ER, Ekumankama O. Eclampsia and seasonal variation in the tropics - a study in Nigeria. Pan African Med J. 2009;2(7):1-6.

16. Praxton A, Maine D, Hijab N. Using the UN process indicators of emergency obstetric services questions and answers. Aver Mat Death Disabil Program. 2003:6.

17. Robson SC. Hypertension and renal disease in pregnancy. In: Edmonds DK (ed.) Dewhurst's Textbook of Obstetrics and Gynaecology for postgraduates, sixth edition. Blackwell science Ltd, London; 1999:166-185.

18. Ekele BA, Badung SLH. Is serum magnesium estimate necessary in patients with eclampsia on magnesium sulphate? Afr J Reprod Health. 2005;9(1):128-32.

19. Efetie ER, Okafor UV Maternal outcome in eclamptic patients in Abuja, Nigeria A 5-year Review. Niger J Clin Prac. 2007;10(4):309-13.

20. Egeonu RO, Obiechina NJA, Okolie VE. Eclampsia and its fatality associations In Nnamdi Azikiwe University Teaching Hospital, Nnewi. J Dent Med Sci. 2017;16(5):111-6.

21. Kechebelu JI, Okoli CC. Review of eclampsia at the Nnamdi Azikiwe University Teaching Hospital, Nnewi. (January 1996-December 2000). J Obstet Gynaecol. 2002;22(3):287-90.

22. Altman D, Carroll G, Duley L, Farrell B, Moodley J, Neilson J, Smith D. Do women with pre-eclampsia, and their babies, benefit from magnesium sulphate? The Magpie Trial: a randomized placebo-controlled trial. Lancet. 2002;359(9321):1877-90.

23. Obed SA, Wilson JB, Elkins TE. Eclampsia: 134 consecutive cases. Int $\mathrm{J}$ Gynecol Obstet. 1994;45(2)97-103.

24. Hlimi T. Association of anemia, pre-eclampsia and eclampsia with seasonality: a realist systematic review. Health Place. 2015;180-92.

25. Jamelle RN. Eclampsia: is there a seasonal variation? J Obstet Gynaecol. 1998;24(2):121-8.

26. Kullima AA, Kawuwa MB, Audu BM, Usman H, Geidam AD. A 5-year review of maternal mortality associated with eclampsia in a tertiary institution in northern Nigeria. Ann African Med. 2009;8(2):81-4.

27. Elongi JP, Tandu B, Spitz B, Verdonck F. Influence of the seasonal variation on the prevalence of preeclampsia in Kinshasa. Gynecol Obstet Fertil. 2011;39:132-5.

28. Wacker J, Schulz M, Fruhauf J, Chiwora FM, Solomayer E, Bastert G. Seasonal change in the incidence of preeclampsia in Zimbabwe. Acta Obstet Gynecol Scand. 1998;77:712-6.

29. United N. The Millennium Development Goals Report 2014. New York: United Nations; 2014. 
30. Brantsaeter AL, Haugen M, Samuelsen SO, Torjusen H, Trogstad L, Alexander J. A dietary pattern characterized by high intake of vegetables, fruits, and vegetable oils is associated with reduced risk of preeclampsia in nulliparous pregnant norwegian women. J Nutr. 2009;139(6):1162-6.
Cite this article as: Ikeanyi EM, Abasi IJ. Eclampsia: a comparative study in a tertiary hospital setting in South-South Region of Nigeria. Int $\mathbf{J}$ Reprod Contracept Obstet Gynecol 2020;9:2356-63. 